\title{
Corrosion Behavior of X100 Pipeline Steel and Its Heat-Affected Zones in Simulated acidic Soil Solution
}

\author{
Yong Yang, Xiushan Shi, Ming Sun, Weiguo Zeng* \\ China Special Equipment Inspection and Research Institute, Beijing 100029, China \\ *E-mail: 39530354@qq.com
}

doi: $10.20964 / 2020.11 .43$

Received: 18 June 2020 / Accepted: 13 August 2020 / Published: 30 September 2020

\begin{abstract}
Different thermal cycle times, peak temperatures, and cooling rates were used in a Gleeble thermomechanical processing machine to simulate the coarse-grained heat-affected zones (CGHAZ) and inter-critically reheated coarse-grained heat-affected zones (ICCGHAZ) of X100 pipeline steel. The corrosion behavior of the X100 pipeline base steel and the heat-affected zones (HAZs) were studied in a simulated acidic soil solution. Open circuit potential (OCP) measurements, potentiodynamic polarization, electrochemical impedance spectroscopy (EIS), scanning electron microscopy (SEM), energy dispersive x-ray spectroscopy (EDS), and weight loss testing were used to characterize the corrosion behavior of X100 pipeline steel and its CGHAZ and ICCGHAZ in a simulated acidic soil solution. The microstructures of the CGHAZ and ICCGHAZ were found to be significantly different from that of the base steel. The original X100 pipeline steel showed the most positive OCP, the lowest polarization resistance, and the highest corrosion rate. The ICCGHAZ showed the most negative OCP, but CGHAZ showed the highest polarization resistance and the lowest corrosion rate. The corrosion products of X100 pipeline steel base material, CGHAZ and ICCGHAZ all form a layer covered with cracks, which provides poor protection for the substrate. Immersed in a simulated acidic soil solution, the X100 pipeline steel base metal samples were uniformly corroded, while CGHAZ and ICCGHAZ suffered severe intergranular corrosion.
\end{abstract}

Keywords: X100 pipeline steel, Heat-Affected Zones, corrosion behavior, simulated acidic soil solution, intergranular corrosion

\section{$\underline{\text { FULL TEXT }}$}

(C) 2020 The Authors. Published by ESG (www.electrochemsci.org). This article is an open access article distributed under the terms and conditions of the Creative Commons Attribution license (http://creativecommons.org/licenses/by/4.0/). 